\title{
Prophylaxis against infection in Singaporean prostitutes
}

\author{
C S BRADBEER,* R N THIN,* T TAN, $\dagger$ T THIRUMOORTHY $\dagger$ \\ From the *Department of Genitourinary Medicine, St Thomas's Hospital, London, and †Middle Road Hospital, \\ Singapore
}

SUMMARY One hundred prostitutes were interviewed about the prophylactic measures they took against infection. The use of contraceptive diaphragms and clandestine antibiotics correlated significantly with fewer gonococcal infections.

In Singapore most infected men cite prostitutes as the source of their sexually transmitted disease.' Prostitutes are encouraged to have regular examinations for gonorrhoea and syphilis, and these infections are treated promptly when found. It would, however, be better to prevent prostitutes acquiring infections. Earlier studies have shown that the clandestine use of antibiotics reduces the number of infections, ${ }^{2}$ but this method of prevention is clearly unacceptable and may contribute to the increase in the incidence of infections with penicillinase producing Neisseria gonorrhoeae. We attempted to discover what methods of prophylaxis were currently in use and to ascertain their effectiveness. We hoped thereby to develop a cheap and effective method of prophylaxis that would be acceptable to most of the prostitutes.

\section{Patients and methods}

We interviewed 100 prostitutes attending Middle Road Hospital, Singapore, about their methods of preventing infection. Prostitutes were included if they had been regular attenders (at least 15 visits in the preceding 12 months). Structured interviews through an interpreter were carried out. Each woman was asked how much she charged, whether she used a diaphragm, antibiotics, or antiseptic washing, and to give a rough percentage of clients using condoms. The number of episodes of gonorrhoea in the preceding 12 months was obtained from her medical records.

Address for reprints: Dr C S Bradbeer, Department of Genitourinary Medicine, St Thomas's Hospital, Lambeth Palace Road, London SE1 7EH

Accepted for publication 13 April 1987

\section{Results}

Antiseptic solutions were used by 67 of the women to wash themselves after intercourse. Most popular were Dettol, Listerine and pHisohex; douching was rarely practised. Of 31 prostitutes who used antibiotics, 19 obtained drugs purporting to be antibiotics from drug stores or pedlars and 12 used medically prescribed drugs inappropriately. Doses were about one tablet a week, although four women received monthly injections. The drugs were usually capsules containing ampicillin or tetracycline, although inert substances could easily have been substituted. Sixteen prostitutes used contraceptive diaphragms with every client.

The mean number of infections for each prophylactic group is shown in the table. The use of antibiotics was significantly associated with fewer episodes of gonorrhoea (means $0.55 v 1.49 ; \mathrm{p}<0.01$ ), as was the use of the diaphragm $(0.50 v 1.39 ; \mathrm{p}<0.05)$. No other methods of prophylaxis showed a difference in numbers of episodes. There was no difference in the number of clients of women in the different groups. Of the 59 women using neither diaphragms nor antibiotics, half said that between a quarter and half of their clients used condoms and a quarter said that fewer than a quarter of their clients used condoms. There was no statistical correlation between the number of infections and the number of clients using condoms.

\section{Discussion}

The study suggests that the use of diaphragms by prostitutes is the best means of preventing infection in the women, and thus breaking the chain of spread. We considered only gonorrhoea, but the same method 
Table Mean yearly incidence of gonorrhoea in groups of prostitutes using different prophylactic measures

\begin{tabular}{|c|c|c|c|c|}
\hline $\begin{array}{l}\text { Prophylactic } \\
\text { measure }\end{array}$ & No & $\begin{array}{l}\text { Mean No of } \\
\text { clients/day }\end{array}$ & $\begin{array}{l}\text { Mean No of } \\
\text { episodes of } \\
\text { gonorrhoeal } \\
\text { year }\end{array}$ & $\begin{array}{l}\text { Difference } \\
\text { in episodes }\end{array}$ \\
\hline $\begin{array}{l}\text { Antibiotics } \\
\text { Yes } \\
\text { No }\end{array}$ & $\begin{array}{l}31 \\
69\end{array}$ & $\begin{array}{l}3.83 \\
5 \cdot 17\end{array}$ & $\begin{array}{l}0.55 \\
1.49\end{array}$ & $\mathrm{p}<0.01$ \\
\hline $\begin{array}{l}\text { Diaphragm: } \\
\text { Yes } \\
\text { No }\end{array}$ & $\begin{array}{l}16 \\
84\end{array}$ & $\begin{array}{l}5 \cdot 56 \\
4 \cdot 60\end{array}$ & $\begin{array}{l}0.50 \\
1.39\end{array}$ & $\mathrm{p}<0.05$ \\
\hline $\begin{array}{l}\text { Diaphragm }+ \\
\text { antibiotic: } \\
\text { Both } \\
\text { Neither }\end{array}$ & $\begin{array}{r}6 \\
59\end{array}$ & $\begin{array}{l}3.58 \\
4.90\end{array}$ & $\begin{array}{l}0.16 \\
1.57\end{array}$ & $\mathrm{p}<0.05$ \\
\hline $\begin{array}{l}\text { Postcoital } \\
\text { washing: } \\
\text { Yes } \\
\text { No }\end{array}$ & $\begin{array}{l}66 \\
34\end{array}$ & $\begin{array}{l}4.67 \\
4.92\end{array}$ & $\begin{array}{l}1.04 \\
1.53\end{array}$ & NS \\
\hline $\begin{array}{l}\text { Cotton wool } \\
\text { insert: } \\
\text { Yes } \\
\text { No }\end{array}$ & $\begin{array}{r}9 \\
91\end{array}$ & $\begin{array}{l}3.44 \\
4.88\end{array}$ & $\begin{array}{l}1.22 \\
1.21\end{array}$ & NS \\
\hline
\end{tabular}

may also prevent chlamydial infection. Swabs were taken only from the cervix and rectum, so there was no information about urethral gonorrhoea.

We are surprised that the use of the other barrier method, condoms, did not correlate with the number of infections. Other studies have shown that the use of condoms can significantly reduce gonorrhoea in men and, by inference, in women too. ${ }^{3}$ There are several possible explanations for this observation; the women may have wrongly estimated the percentage of clients using condoms, or the condoms may have been incorrectly used. Condom users and non-condom users may represent different groups, the latter being less responsible and less aware members of the community who are more likely to have acquired an infection in the first place through non-use of condoms and are less likely to take any action when symptoms develop.

We confirm the findings of Goh et al, who studied Singaporean prostitutes in 1980-81, that prophylaxis with antibiotics reduced the number of attacks of gonorrhoea, ${ }^{2}$ although only $31 \%$ of our patients, compared with $60 \%$ of theirs, used these drugs. This difference was in illicitly obtained drugs; the proportion of prostitutes using chemoprophylaxis medically prescribed was the same in both studies.

Two methods of prophylaxis were shown to reduce the incidence of gonorrhoea in this population. One was the use of antibiotics, and this is clearly unsatisfactory. The other was the use of the diaphragm; this is cheap and relatively easy to use. A quarter of the prostitutes were already using some sort of insert (16 used diaphragms, and nine used cotton wool inserts), so acceptability is likely to be high. If further work confirms our findings, these women could be fitted with a diaphragm at their first routine clinic visit.

\section{References}

1 Thirumoorthy T, Sng EH, Doraisingham S, Ling AE, Lim KB, Lee CT. Purulent penile ulcers of patients in Singapore. Genitourin Med 1986;62:253-5.

2 Goh CL, Meija P, Sng EH, Rajan VS, Thirumoorthy T. Chemoprophylaxis and gonococcal infections in prostitutes. Int J Epidemiol 1984;13:344-6.

3 Barlow D. The condom and gonorrhoea. Lancet 1977;ii:811-3. 